\title{
The histone methyltransferase ESET is required for the survival of spermatogonial stem/progenitor cells in mice
}

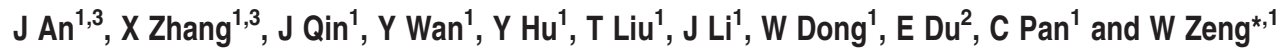

Self-renewal and differentiation of spermatogonial stem cells (SSCs) are the foundation of spermatogenesis throughout a male's life. SSC transplantation will be a valuable solution for young male patients to preserve their fertility. As SSCs in the collected testis tissue from the patients are very limited, it is necessary to expansion the SSCs in vitro. Previous studies suggested that histone methyltransferase ERG-associated protein with SET domain (ESET) represses gene expression and is essential for the maintenance of the pool of embryonic stem cells and neurons. The objective of this study was to determine the role of ESET in SSCs using in vitro cell culture and germ cell transplantation. Cell transplantation assay showed that knockdown of ESET reduced the number of seminiferous tubules with spermatogenesis when compared with that of the control. Knockdown of ESET also upregulated the expression of apoptosis-associated genes (such as P53, Caspase9, Apaf1), whereas inhibited the expression of apoptosis-suppressing genes (such as Bc/211, X-linked inhibitor of apoptosis protein). In addition, suppression of ESET led to increase in expression of Caspase9 and activation of Caspase3 (P17) as well as cleavage of poly (ADP-ribose) polymerase. Among the five ESET-targeting genes (Cox4i2, spermatogenesis and oogenesis Specific Basic Helix-Loop-Helix 2, Nobox, Foxn1 and Dazl) examined by ChIP assay, Cox4i2 was found to regulate SSC apoptosis by the rescue experiment. BSP analyses further showed that DNA methylation in the promoter loci of Cox4i2 was influenced by ESET, indicating that ESET also regulated gene expression through DNA methylation in addition to histone methylation. In conclusion, we found that ESET regulated SSC apoptosis by suppressing of Cox4i2 expression through histone H3 lysine 9 tri-methylation and DNA methylation. The results obtained will provide unique insights that would broaden the research on SSC biology and contribute to the treatment of male infertility.

Cell Death and Disease (2014) 5, e1196; doi:10.1038/cddis.2014.171; published online 24 April 2014

Subject Category: Cancer

Self-renewal and differentiation of spermatogonial stem cells (SSCs) are the foundation of spermatogenesis throughout a male's life. In mouse, SSCs were arisen from gonocytes at postnatal days 3-8 and considered as a subpopulation of the most undifferentiated spermatogonia (As spermatogonia). ${ }^{1,2}$ As spermatogonia are able to divide into new As spermatogonia or A-paired (Apr) spermatogonia that remain connected by an intercellular bridge. The Apr spermatogonia divide into chains of A-aligned (Aal) spermatogonia. The Aal form A1-A4 spermatogonia and then intermediate and type B spermatogonia. ${ }^{3}$ SSCs are rare in testes, isolation and purification of the SSCs is challenging. In adult rodents, only $0.02-0.03 \%$ of the total germ cells have stem cell capacity. ${ }^{4}$ Fortunately, a few of surface marker were identified in mouse SSCs such as Thy1, GDNF family receptor alpha 1 and integrin, Alpha 6, which can be used for purification of SSCs by fluorescent- activated cell sorting or magnetic-activated cell sorting (MACS). ${ }^{5-8}$

SSC transplantation was established in 1994. ${ }^{9,10}$ Donor SSCs can be transplanted into recipient mice and initiate the process of spermatogenesis. In clinical, SSC transplantation will be a valuable solution for young male patients to preserve their fertility. ${ }^{11,12}$ Adolescents and adult men have the option of cryopreservation of their semen before cancer treatment, but prepubertal boys cannot benefit from this approach since their spermatogenesis have not completed. Luckily, collection of the testis tissue before radiation- or chemo-therapy and transplantation of SSCs back into their seminiferous tubules after the therapy would recover the patients' spermatogenesis. As the SSCs in the collected testis tissue from the patients are very limited, it is necessary to expansion the SSCs in vitro.

\footnotetext{
${ }^{1}$ College of Animal Science and Technology, Northwest A\&F University, Shaanxi, China and ${ }^{2}$ College of Veterinary Medicine, Northwest A\&F University, Shaanxi, China ${ }^{*}$ Corresponding author: W Zeng, College of Animal Science and Technology, Northwest A\&F University, No.22 Xinong Road, Yangling, Shaanxi 712100, China. Tel: +86 029 87091932; Fax: +86 029 87091932; E-mail: zengwnxian@ hotmail.com

${ }^{3}$ These authors contributed equally to this work.

Keywords: spermatogonial stem cell; ESET; H3K9me3; apoptosis

Abbreviations: Apaf1, apoptotic protease activating factor 1; ChIP, chromatin immunoprecipitation; Cox4i2, cytochrome coxidase subunit IV isoform 2; Dazl, deleted in azoospermia-like; ESET, ERG-associated protein with SET domain; GDNF, glial cell line-derived neurotrophic factor; H3K9me3, Histone H3 lysine 9 tri-methylation; KD, knockdown; MACS, magnetic-activated cell sorting; PARP, poly (ADP-ribose) polymerase; Plzf, promyelocytic leukemia zinc-finger; shRNA, small hairpin RNA; Sohlh2, spermatogenesis and oogenesis specific basic helix-loop-helix 2; SSCs, spermatogonial stem cells; TUNEL, terminal deoxynucleotidyl transferase-mediated dUTP nick-end labeling

Received 11.2.14; revised 17.3.14; accepted 18.3.14; Edited by A Stephanou
} 
Research has identified several signaling pathways as well as a number of transcription factors to play essential roles in the maintenance of SSCs. Glial cell line-derived neurotrophic factor (GDNF) has been identified as a critical factor in vivo for the replication of SSCs ${ }^{13,14}$ and a primary regulator of the fate decision for SSCs in vitro. ${ }^{15,16}$ GDNF-regulated transcriptional factors, for example B-cell CLL/lymphoma 6, member B, are crucial for SSC maintenance in vitro. ${ }^{17}$ In addition, promyelocytic leukemia zinc-finger protein (PIzf), a GDNFindependent transcriptional factor, is also required for SSC maintenance because mice with mutant Plzf show progressive loss of SSCs, leading to sterility. ${ }^{18,19}$ Meanwhile, it was reported that epigenetic regulation also played an important role in the maintenance of SSCs. For example, the abnormal expression of DNA methyltransferase led to spermatogenic defects, ${ }^{20}$ and JMJD3 (a histone H3K27 demethylase) regulated fragmentation of spermatogonial cysts. ${ }^{21}$ However, what role histone modification play in the maintenance of SSCs remains unknown.

Histone proteins consist mainly of flexible amino-terminal tails protruding outward from the nucleosome, and globular carboxy-terminal domains making up the nucleosome scaffold. ${ }^{22}$ A variety of modifications occur throughout the histone proteins on the $\mathrm{N}$-terminal tail including phosphorylation, ubiquitination, acetylation and methylation, which play important roles in chromatin remodeling, gene transcriptional regulation, stem cell maintenance and differentiation. ${ }^{23-26}$ Histone $\mathrm{H} 3$ lysine 9 tri-methylation (H3K9me3) is one of the most highly studied covalent modifications and has functions in the repression of genes, most likely via acting as a recognition motif for the binding of chromatin-associated proteins. $^{27}$

The histone methyltransferase ERG-associated protein with SET domain (ESET) (also known as SETDB1 or KMT1E) represses gene expression through $\mathrm{H} 3 \mathrm{~K} 9 \mathrm{me2} / 3 .{ }^{28,29} \mathrm{ESET}$ has shown to be vital for the maintenance of embryonic stem cells (ESCs). ${ }^{30}$ Furthermore, ESET plays essential roles both in the maintenance of articular cartilage and survival of neurons. ${ }^{31,32}$ As conventional ablation of the Eset gene leads to embryonic lethality, ${ }^{33}$ the functions of ESET in spermatogenesis have not been examined extensively.

The objective of this study was to determine the role of ESET in SSCs using in vitro cell culture and germ cell transplantation. We found that ESET regulated SSCs apoptosis by suppression of cytochrome $c$ oxidase subunit IV isoform 2 (Cox4i2) expression through H3K9me3 and DNA methylation. Our data demonstrated, for the first time, that ESET regulated gene expressions in SSCs via modulation of H3K9me3, implicating that ESET was a novel epigenetic regulator for SSCs. The results obtained will further broaden the research on SSC biology and provide new idea for the treatment of male infertility.

\section{Results}

Global level and distribution of ESET and H3K9me3 in mouse testis tissue. Eset transcripts were detected at high levels in testis, while at low levels in heart and kidney (Figure 1a). To detect the global level of ESET and H3K9me3 in spermatogenesis, qRT-PCR and western blot using multiple tissues from testis at different developmental stages were performed. The expression of ESET was gradually increasing during testis development, in parallel to the global level of H3K9me3 (Figures $1 \mathrm{~b}$ and $\mathrm{c}$ ).

We further examined the distribution of ESET and H3K9me3 in SSCs by co-immunofluorescence staining. The result showed both ESET and $\mathrm{H} 3 \mathrm{~K} 9 \mathrm{me} 3$ were presented in SSCs (positive for PLZF or Thy1, Figure 1d and Supplementary Figure S1). Interestingly, distinct distribution of $\mathrm{H} 3 \mathrm{~K} 9 \mathrm{me} 3$ was observed in mouse testis. H3K9me3 displayed an exclusively perinuclear distribution in SSCs while localized to punctate foci in differentiated spermatogonia (positive for KIT, Figure 1d), which is consistent with previous reports. ${ }^{34}$ As a heterochromatin marker, ${ }^{35}$ this unique distribution of $\mathrm{H} 3 \mathrm{~K} 9 \mathrm{me} 3$ may be used to distinguish SSCs and the differentiated spermatogonia in mouse testis.

ESET is a negative regulator of SSC maintenance. As the population of SSCs in the testis is very low, MACS using antiThy1 IgG-conjugated microbeads was performed to enrich SSCs. The purity of the isolated cells was $92 \%$ as indicated by immunocytochemistry for Thy1 (Figures 2a and b). To reveal the role of ESET in SSCs, RNA interference using lentiviral vectors coding for short hairpin (sh) RNAs directed against Eset was performed in primary SSCs. The expression of ESET in Eset-small hairpin RNA (shRNA) lentiviral transduced SSCs was significantly reduced examined by qRT-PCR (Figure 2c) and western blot (Figure 2d). In addition, we found that depletion of ESET resulted in deduction of H3K9me3 (Figure 2d), suggesting that ESET is required for the maintenance of $\mathrm{H} 3 \mathrm{~K} 9 \mathrm{me} 3$ in SSCs.

SSCs were enriched through MACS, transduced with EsetshRNA lentiviral particles and cultured on feeder layer of Sertoli cells. Following 2-week cultivation in vitro, the number of SSCs in ESET-knockdown (KD) group (transduced with Eset-shRNA lentivirus) was significantly reduced compared with the control (transduced with scrambled shRNA lentivirus or no lentivirus infection) (Figures $2 \mathrm{f}-\mathrm{h}$ ). Immunofluorescence for Lin28 was performed to further confirm the SSCs number post culture in vitro (Figures $2 \mathrm{i}-\mathrm{k}$ ). It has reported that Lin28, as a pluripotency factor, was specifically expressed in As, Apr and Aal spermatogonia, which were widely considered as SSCs in mouse. ${ }^{2}$ Lin28 was used as a SSCs marker in the previous studies and has been shown to be associated with stemness of SSCs. ${ }^{36-40}$ In our experiments, Lin28 was used to distinguish the undifferentiated spermatogonia from other types of cells(such as Sertoli cell and differentiated spermatogonia).The result showed that Lin28-positive cells in ESETKD group were significantly reduced (Figure 2e), suggesting ESET deficiency led to decrease of the number of SSCs probably because of apoptosis or differentiation.

Transplantation assay showed that ESET was essential for SSC maintenance in vivo. To test whether ESET regulates the maintenance of SSCs in vivo, we applied the assay of SSC transplantation. SSCs were enriched through MACS, seeded on laminin-coated plates and transduced with Eset-shRNA lentiviral particles. Two days later, cells were transplanted into recipient mouse testis that was previously treated with busulfan to deplete endogenous germ cells 
a

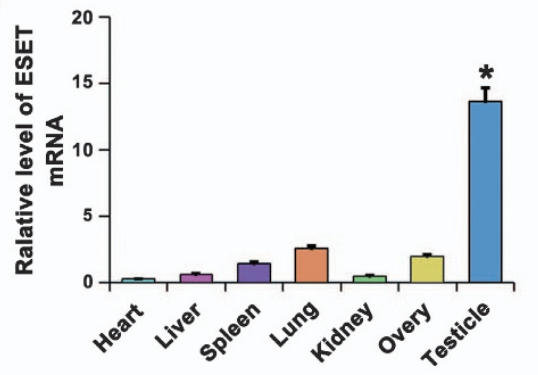

b

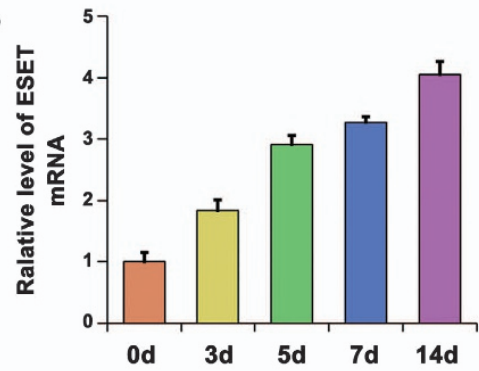

C

ESET

$\beta$-actin
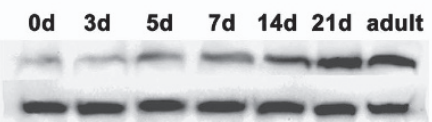

0d 3d 5d 7d 14d 21d adult

H3K9me3

H3 histone d

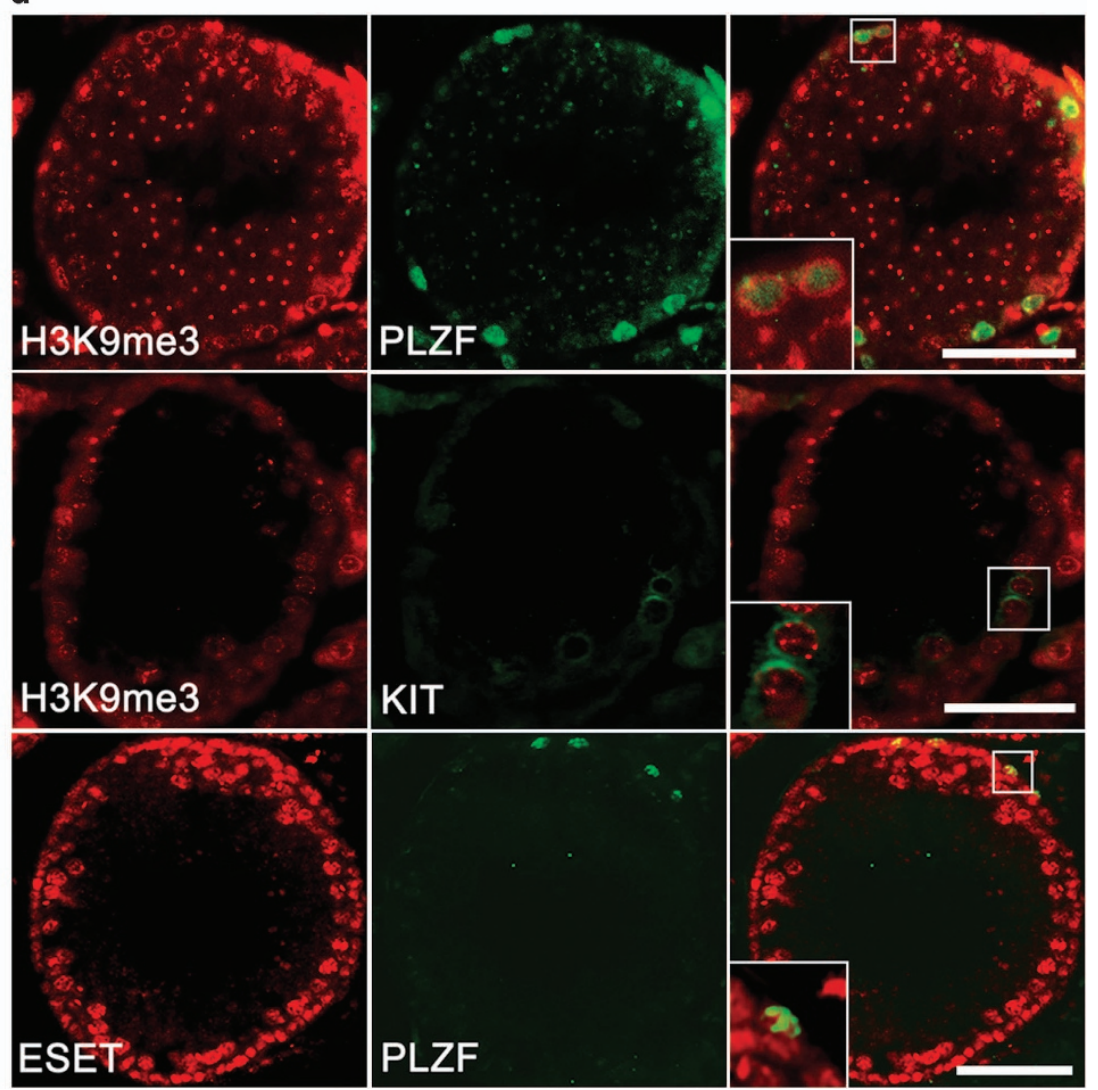

Figure 1 Global level and co-immunofluorescence localization of H3K9me3 and ESET. Transcripts of Eset were examined by qRT-PCR in multiple tissue samples (a) and during postnatal development of the testis (b). Values were normalized to that of Gapdh. ${ }^{*} P<0.05$ compared with other tissues. (c) ESET expression and H3K9me3 level were examined by western blot during postnatal development of the testis. (d) Co-immunofluorescence localization of H3K9me3/ESET (red) and PLZF/KIT (green) in SSCs and differentiated spermatogonia. Bar $=100 \mu \mathrm{m}$. White line boxes were shown at higher magnification

(Figures $3 a$ and b). At 10 weeks post surgery, the weight of testes from recipient mice transplanted with ESET-KD SSCs was less than that of those transplanted with NC SSCs or Mock SSCs (no lentivirus transduction) $(P<0.05)$ (Figures $3 \mathrm{c}$ and $\mathrm{d}$ ).

We examined further the spermatogenesis in the recipient mice. Seminiferous tubules showing spermatogenesis were analyzed according to the previous reports. ${ }^{41,42}$ The number of seminiferous tubule with (at least two layers of germ cells) or without spermatogenesis was counted for measuring the recovery of spermatogenesis. The result showed the number of seminiferous tubules showing spermatogenesis in ESET$\mathrm{KD}$ group was lower than that in the control groups (Figures $3 e$ and f). These data suggested that in the control groups, SSCs could home in the basement membrane of seminiferous tubules and initiate spermatogenesis, but SSCs in the ESETKD group could not do so.

Since the lentiviral backbone contained an EF-1 $\alpha /$ GFP expression cassette, GFP expression would mirror the transplanted SSCs that were tranduced with lentiviral vectors successfully and their progeny cells in the seminiferous tubules. Expression of GFP and PLZF significantly reduced in the ESET-KD group, indicating that the number of transplanted SSCs in recipient mice testis was reduced upon depletion of ESET (Figure $3 \mathrm{~g}$ ). These observations were consistent with the in vitro experiments (Figure 2e), indicating that ESET was essential for the survival of SSC.

ESET depletion induces SSC apoptosis. SSCs were enriched through MACS and transduced with lentiviral shRNA expression construct as above. Following 1-week cultivation in vitro, terminal deoxynucleotidyl transferasemediated dUTP nick-end labeling (TUNEL) assay was applied to detect apoptotic cells. The results showed that the number of apoptotic cells in ESET-KD group was significantly increased (Figures $4 a$ and b), suggesting ESET regulated the apoptosis of SSCs. The above data also suggested that apoptosis might be one of key reasons in reduction of the number of SSCs after ESET depletion both in vivo and in vitro.

cDNA microarray analysis was further performed to screen the genes modulated by ESET. RNA was isolated from the 1 -week cultured cells. Interestingly, the expression of apoptosisassociated genes such as P53, Caspase9, apoptotic protease activating factor 1 (Apaf1) was upregulated, whereas that of apoptosis -suppressed genes such as Bc/2/1, X-linked inhibitor of apoptosis protein was downregulated. The changes in expression of the aforementioned genes were further validated by qRT-PCR (Figure 4c). In addition, western blot assay showed that the suppression of ESET led to increase in 
a

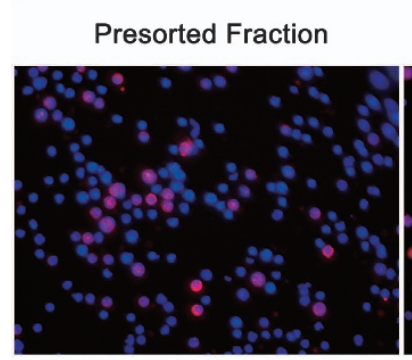

b
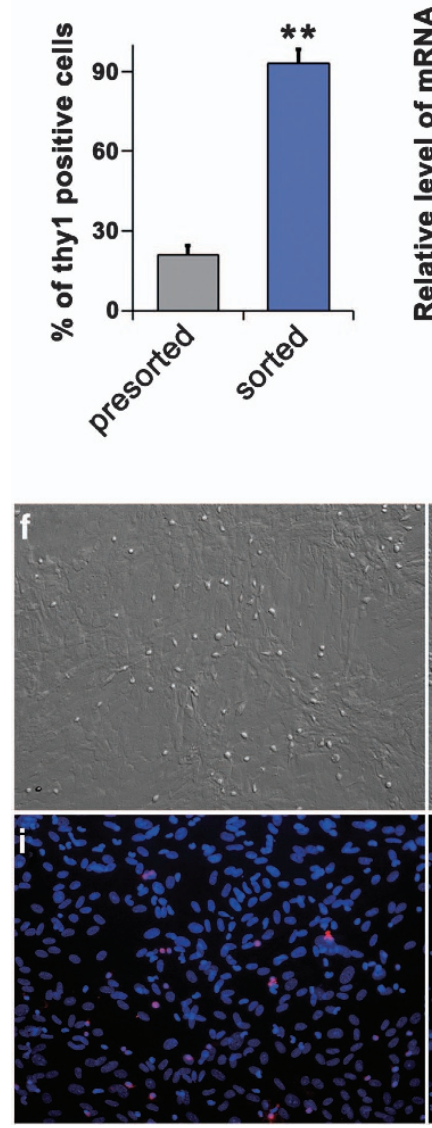

c
Sorted Fraction
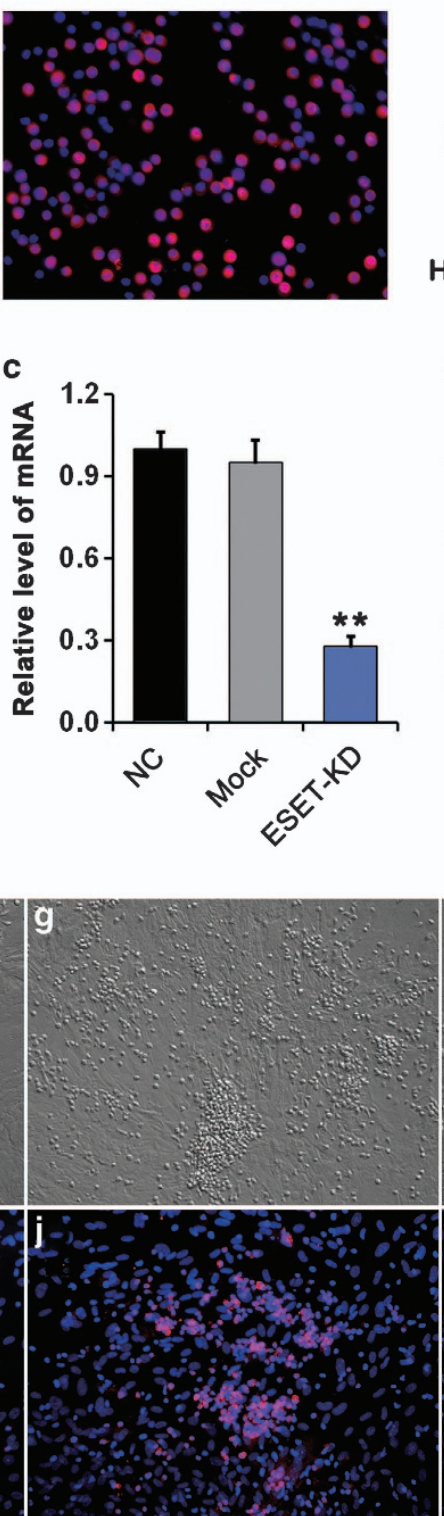

d

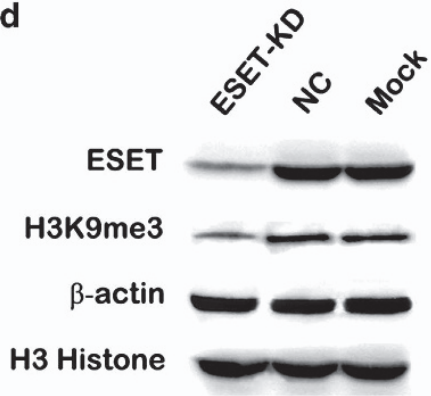

e

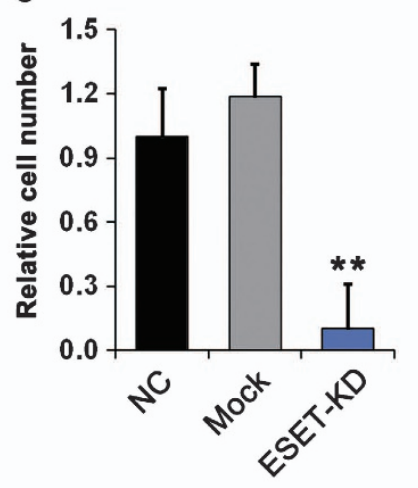

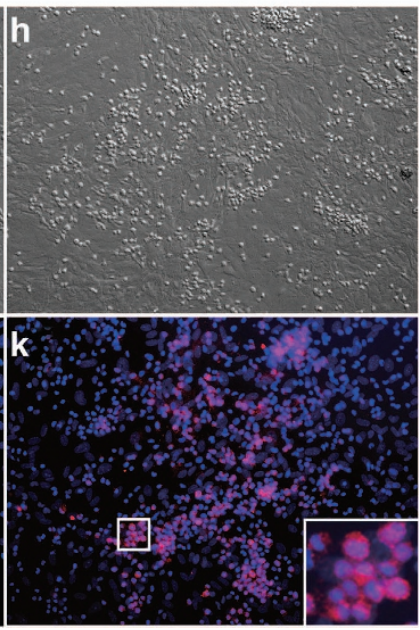

Figure 2 MACS and RNAi efficiency and SSC culture in vitro. (a) Immunofluorescence of Thy1 (red) and DAPI (blue) in presorted and two-step sorted cells. Bar $=80 \mu \mathrm{m}$. (b) Proportion of Thy1-positive cells in presorted and two-step sorted fraction $(n=4)$. More than 350 cells were counted for each sample. Asterisks indicate statistically significant differences ( ${ }^{* *} P<0.01$ ). (c) qRT-PCR analysis of Eset expression in the ESET-KD, NC and Mock SSCs group. Values were normalized to that of Gapdh, ${ }^{* *} P<0.01$ compared with NC or Mock controls. (d) ESET and global H3K9me3 level were slightly decreased in the ESET-KD SSCs, examined by western blot. (e) Relative number of Lin28-positive cells in ESET-KD, NC and Mock SSC groups after 2 weeks culture. Five thousands of SSCs for each treatment were plated in multiple wells of a 96-well plate and cultured for 2 weeks $(n=3)$. The number of Lin28-positive cells in ESET-KD group was lower than that in NC and Mock group ( $\left.{ }^{* *} P<0.01\right)$. (f-k) Culture of SSCs after transduced with lentiviral. ESET-KD SSCs ( $\mathbf{f}$ and $\mathbf{i}$ ), NC group ( $\mathbf{g}$ and $\mathbf{j}$ ) and Mock group ( $\mathbf{h}$ and $\mathbf{k}$ ) were analyzed after 2 weeks culture. Immunofluorescence for Lin28 (red) and DAPI (blue) were performed to count the number of SSCs (i-k). Bar $=80 \mu \mathrm{m}$

expression of Caspase9 and activation of Caspase3 (P17) as well as cleavage of poly (ADP-ribose) polymerase (PARP) (Figure 4d). These data suggested the scenario for SSC apoptosis by ESET depletion might initiate from upregulating apoptosis inducers such as Apaf1, Caspase9 and downregulating apoptosis suppressors such as Bcl2/1, X-linked inhibitor of apoptosis protein to promote assembly of the apoptosome complex, and in turn activating the effector Caspase 3 and further causing the cleavage of PARP.
ESET regulated SSC apoptosis by targeting Cox4i2 through increasing $\mathrm{H} 3 \mathrm{~K} 9 \mathrm{me} 3$ and DNA methylaion. To further understand the mechanisms by which ESET regulates SSC apoptosis, we conducted chromatin immunoprecipitation (ChIP) analysis. As it was hard to collect a large number of the primary SSCs for ChIP assay, a spermatogonial stem/progenitor cell line (C18-4 cells) was used in this study. ${ }^{43-45}$ We selected 16 of the upregulated genes from the microarray data and analyzed their proximal 


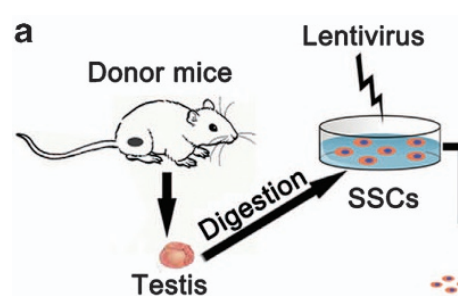

C

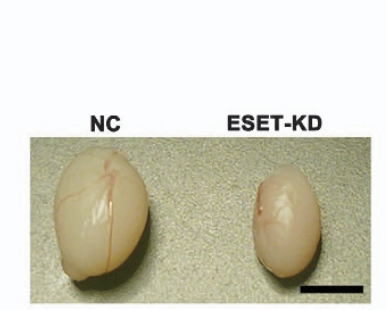

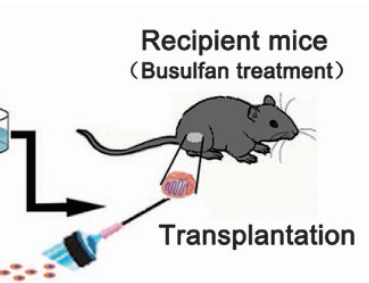

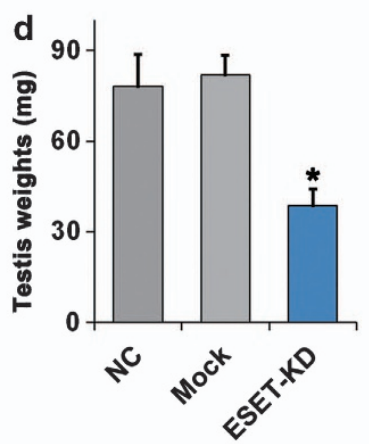

b

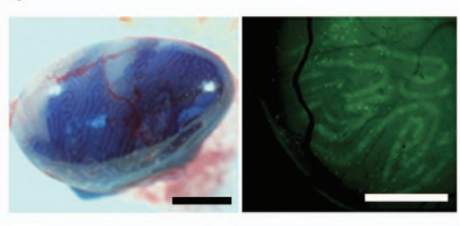

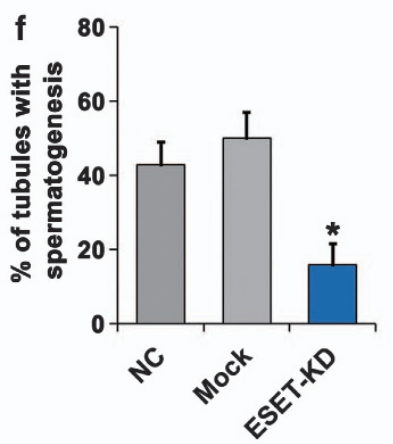

e

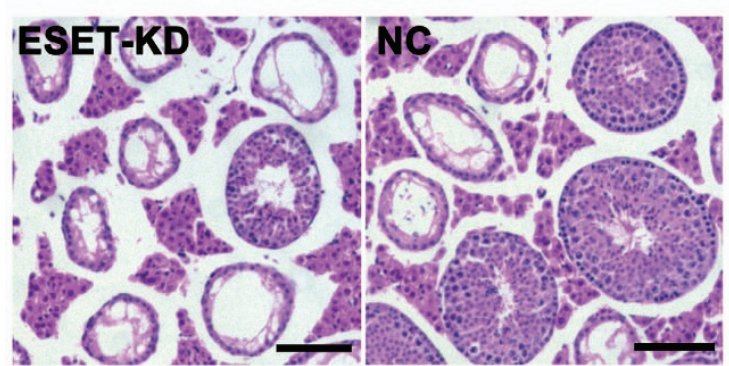

g

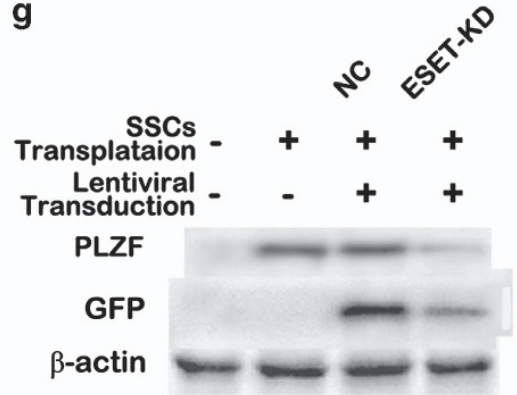

Figure 3 Phenotypic characteristics of recipient testes transplanted with SSCs that were transduced with lentiviral particles. (a) Schematic diagram of the SSC transplantation strategy. (b) After injection, presence of dye in seminiferous tubules confirmed successful injection (left). After 10 weeks, GFP expression in seminiferous tubules indicates donor SSC-derived spermatogenesis (right). Bar $=2 \mathrm{~mm}$. (c) Testis from recipient mice transplanted with ESET-KD SSCs was smaller than that transplanted with NC SSCs. Bar $=4 \mathrm{~mm}$. (d) Testis weights in ESET-KD, NC and Mock group. The values were significantly lower in the ESET-KD group compared with the control groups $\left({ }^{*} P<0.05\right)$. (e) Hematoxylin-eosin staining of the testis tissue transplanted with ESET-KD and NC SSCs. Spermatogenesis was heavily impaired in ESET-KD group. $\operatorname{Bar}=100 \mu \mathrm{m}$. (f) Quantitative measurements of reconstitution of the seminiferous epithelium $(n=3)$. More than five sections and an average of 80 tubules/section were counted for each sample. Asterisk indicates significant differences between the two groups ( $\left.{ }^{*} P<0.05\right)$. (g) Western blot analysis of testis tissue transplanted with ESET-KD SSCs, NC SSCs and Mock SSCs

promoter within $4 \mathrm{~kb}$ upstream from the transcriptional start site. ChIP analysis using anti-ESET IgG showed that ESET bound to the promoter region of five genes (Cox4i2, spermatogenesis and oogenesis specific basic helixloop-helix 2 (Soh/h2), Nobox, Foxn1 and deleted in azoospermia-like (Dazl)) (Figure 5a), the expression of which increased when ESET was knocked down (Supplementary Figure S2), indicating that these five genes were regulated by ESET. However, we did not find that ESET bound to promoter loci of apoptotic inducer Apaf1 and Caspase9 examined by ChIP assay using ESET antibody, although the transcription of these two genes was upregulated in ESET-KD group. Previous studies have shown that CoxIV enrichment were early events preceding the onset of apoptosis and that oxidation of cytochrome $c$ by cytochrome oxidase-stimulated caspase activation. ${ }^{46,47}$ Therefore, among the five ESET-targeting genes, Cox4i2 (also named as CoxIV-2, belongs to the cytochrome $c$ oxidase IV family) may be a mediator for ESET to regulate apoptosis of SSCs.
To further address whether KD of Cox4i2 rescues the cell death phenotype of ESET-KD cells, both siRNA of ESET and Cox4i2 were transfected to C18-4 cells simultaneously. TUNEL assay showed that apoptosis was reduced in cells co-transfected with both siRNA of ESET and Cox4i2 compared with that of only transfected withEset siRNA (Figure 5c). qRT-PCR assay showed that the level of Caspase9 was decreased in co-transfection group (Figure 5d), which is consistent with the TUNEL assay. These observations further suggest that KD of Cox4i2 partially rescues the cell death phenotype of ESET-KD cells and ESET may indirectly regulate Caspase 9 via Cox4i2 and influence SSC apoptosis.

Interestingly, ChIP experiment using H3K9me3 antibody revealed that $\mathrm{H} 3 \mathrm{~K} 9 \mathrm{me} 3$ in the promoter regions of the regulated genes decreased in ESET-KD treatment (Figure 5b), suggesting that ESET binds to these genes and represses their expression via increased H3K9me3 marks. To further elucidate whether depletion of ESET lead to change of DNA methylation, we performed bisulfite sequencing PCR. 

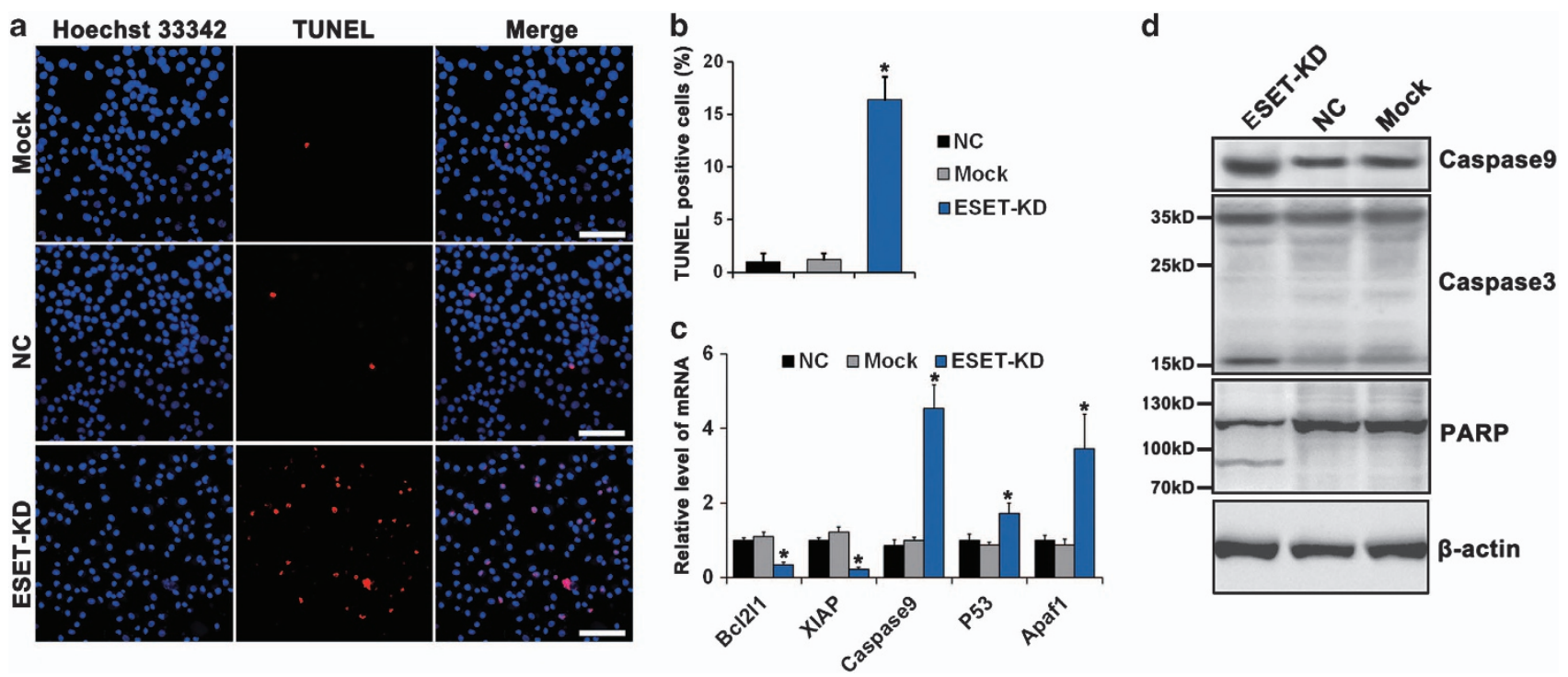

Figure 4 ESET regulated SSC apoptosis via caspase-dependent pathways. (a) TUNEL staining of SSC transduced with Eset-shRNA (ESET-KD), NC-shRNA (NC) or no lentiviral particles (Mock). Red color indicates TUNEL-positive cells. Counterstained with Hoechst 33342 are represented in blue. Bar $=100 \mu \mathrm{m}$. (b) Graphical representation of the number of TUNEL-positive cells $(n=4)$. More than 280 cells were counted for each sample. Asterisks indicate statistically significant differences ( $\left.{ }^{*} P<0.05\right)$. (c) qRTPCR analysis of gene expression in the ESET-KD, NC and Mock SSCs group. Values were normalized to that of Gapdh, ${ }^{\star} P<0.05$ compared with NC or Mock controls. (d) Caspase-dependent apoptosis caused by lacking ESET examined by western blot. Caspase9 and the cleaved Caspase3 level were increased, and with the presence of cleaved PARP in ESET-KD SSCs

DNA methylation at promoter regions of ESET-target genes Cox4i2 and Dazl (co-targeted by ESET and H3K9me3) was analyzed. The results showed that DNA methylation at the Cox4i2 promoter decreased, but did not change at the promoter of Dazl, in ESET-KD cells (Figure 5e), suggesting ESET also regulates Cox4i2 and influence SSC apoptosis by increasing DNA methylation.

\section{Discussion}

SSCs maintain sperm production in the testis throughout adult life. In rodents, SSCs are considered to be a subpopulation of the most undifferentiated spermatogonia: the single type A (As) spermatogona. ${ }^{2}$ The study of the mechanisms regulating SSC fate is challenging because of the rare number and difficulty in genetic manipulation of SSCs. To solve this problem, in this study MACS was applied to enrich SSCs and lentiviral vectors were used to manipulate the purified SSCs. MACS with anti-Thy1 IgG has been successfully enriched SSCs in our laboratory and the other groups. ${ }^{5,48}$ The Thy1positive (as a marker of SSCs) cells were as high as $92 \%$ in the MACS-sorted cells (Figures $2 a$ and b).Short hairpin RNAs can be expressed from lentiviruses, allowing for high transfection efficiency of a variety of cell types, including non-dividing cells and stem cells. ${ }^{49,50}$ It has been reported that lentivirus showed high transduction (about 53.7\%) with an optimized protocol in SSCs. ${ }^{51}$

In this experiment, SSC transplantation was used to study the function of SSCs. SSCs were purified from fertile donors and transplanted into the testes that was previously treated with busulfan to deplete endogenous germ cells. SSCs are able to migrate into the basement membrane of the seminiferous tubules, form colonies and produce sperm cells. SSC transplantation has become a golden standard for detecting functional activities of SSCs and was used for elucidating the molecular mechanisms involved in selfrenewal and differentiation of SSCs. ${ }^{9,10}$ We acquired the purified SSCs from 6-8 days old mice. After lentiviral transduction, SSCs were transplanted into recipient mouse testis. ESET-KD SSCs were under apoptosis and lost the SSC activity, while the control SSCs were able to homing and initiate spermatogenesis. Ten weeks after transplantation, the number of seminferous tubules with spermatogenesis in the control was significant higher than that in the ESET-KD group. The more the seminiferous tubules with spermatogenesis, the more SSCs survived and differentiated.

Since the transduction efficiency of lentivirus was moderate, SSCs, which were not transduced with lentiviral particles in ESET-KD group, were also able to homing and initiate spermatogenesis. Therefore, it would produce background when counting the colonies. To avoid this problem, western blot of GFP were used in this study. Because the lentiviral backbone contained an EF-1 $\alpha$ /GFP expression cassette, only lentiviral transduced SSCs and their progeny cells would show GFP expression. Therefore, the level of GFP in recipient mouse testis can reflect the number of transplanted SSCs with lentiviral transduction. Expression of GFP significantly reduced in the ESET-KD group (Figure $3 \mathrm{~g}$ ), indicating that the number of SSCs in recipient mice testis was reduced upon depletion of ESET.

As well known, once cytochrome $c$ is released into the cytoplasm it binds to Apaf1, which then binds to Caspase9 to form a protein complex known as an apoptosome. Apoptosome is central to the induction of apoptosis through activating the effector Caspase 3 and further causing the cleavage of PARP. In SSCs, as a negative regulator of apoptosis, ESET inhibits assembly of the apoptosome complex through 

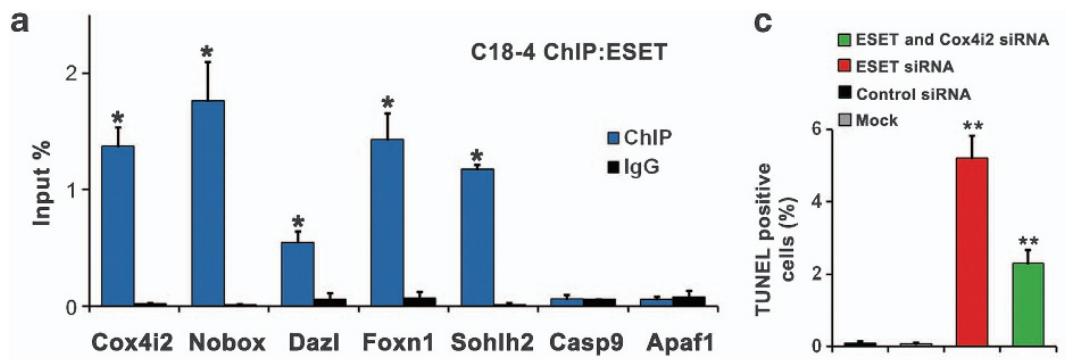

b

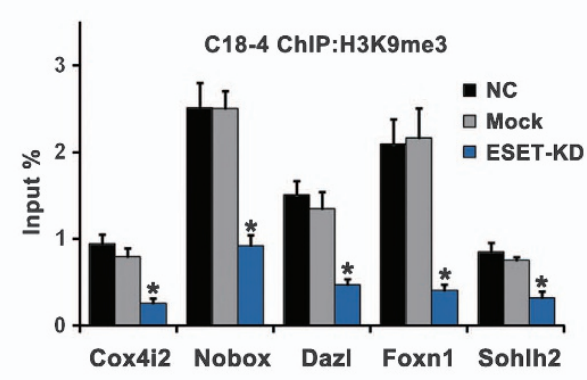

d $\square$ ESET and Cox4i2 siRNA

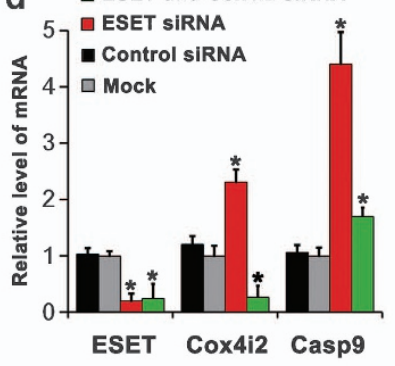

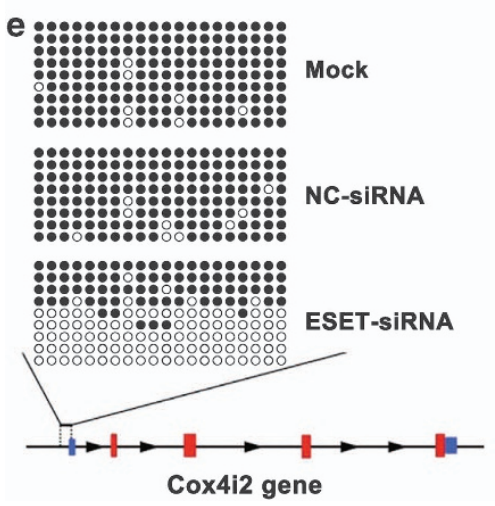
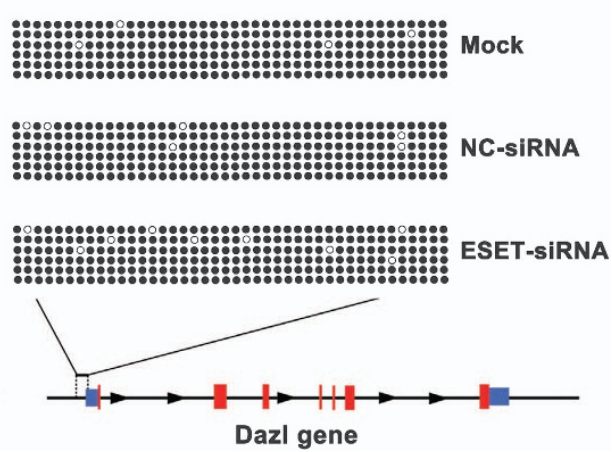

Figure 5 ESET regulated SSCs apoptosis by Cox4i2 through increasing H3K9me3 and DNA methylation. (a) Cross-linked ChIP assay was performed with IgG or antiESET IgG in C18-4 cells and direct binding of ESET on the promoter regions of Cox4i2, Sohlh2, Dazl, Nobox, Foxn1, Capase9 and Apaf1 was detected. ${ }^{*} P<0.05$ compared with IgG group. (b) ChIP assay was performed with $\mathrm{H} 3 \mathrm{~K} 9 \mathrm{me} 3$ antibody in C18-4 cells transfected with Eset-siRNA, NC-siRNA or transfection reagent. Binding activity (relative to the input) of H3K9me3 on promoter regions of Cox4i2, Nobox, Dazl, Foxn1 and Sohlh2 was quantified. ${ }^{*} P<0.05$ compared with NC-siRNA or Mock controls. (c) Graphical representation of the number of TUNEL-positive cells $(n=4)$. More than 256 cells were counted for each sample. Asterisks indicate statistically significant differences $\left({ }^{* *} P<0.01\right)$. (d) Transcripts of Eset, Cox4i2 and Caspase9 were examined by qRT-PCR in C18-4 cells transfected with siRNA. (e) Bisulfite sequencing analysis of Cox4i2 $(-0.5 \mathrm{~kb})$ and Dazl promoter $(-0.5 \mathrm{~kb})$ in $\mathrm{C} 18-4$ cells. The position of $\mathrm{CpG}$ dinucleotide analyzed is indicated by a horizontal line. Open circles, unmethylated $\mathrm{CpG}$; closed circles, methylated $\mathrm{CpG}$

suppression of Apaf1 and Caspase9, and thus influence activation of Caspase 3 and the cleavage of PARP. We noticed that Caspase 9 and the number of apoptotic cells in cotransfection group were also higher than those in the control group, although they were significant lower than those in EsetsiRNA group in the rescue experiment. We speculated that other apoptosis regulatory pathways regulated by ESET may exist in SSCs. On the one hand, ESET may upregulate Caspase9 expression by other target gene(s) in addition to Cox4i2, because depletion of Cox4i2 expression in ESET-KD cell was not able to restore the Caspase9 expression to normal level (Figure 5d). On the other hand, ESET may modulate apoptosis via other pathways. The focus of our present work was to provide a regulation mode of ESET including H3K9me3 and DNA methylation, and the integral mechanisms of apoptosis regulation require further study.
In mammalian cells, $\mathrm{H} 3 \mathrm{~K} 9 \mathrm{me} 3$ is a hallmark of heterochromatin and is important for silencing of genes and retroelements. ${ }^{52}$ In the present study, ChIP assays showed that ESET directly bound to the promoters of the Cox4i2, Sohlh2, Nobox, Foxn1 and Dazl. Furthermore, in the depletion of ESET, the H3K9me3 mark on these gene loci was reduced, leading to upregulation gene expression of Cox4i2, Sohlh2, Nobox, Foxn1 and Dazl. It was reported that the genes upregulated after deletion of ESET in mouse embryonic stem cells (ESCs) are distinct from those derepressed in ESC deficient in the DNA methyltransferases, with the exception of a small number of primarily germline-specific genes (such as Dazl and Cox7b2). ${ }^{53}$ In SSCs, we found Cox4i2 and Dazl showed high level of H3K9me3 and DNA methylation in their promoter region, suggesting these genes were suppressed by H3K9me3 and DNA methylation simultaneously. Interestingly, the DNA 


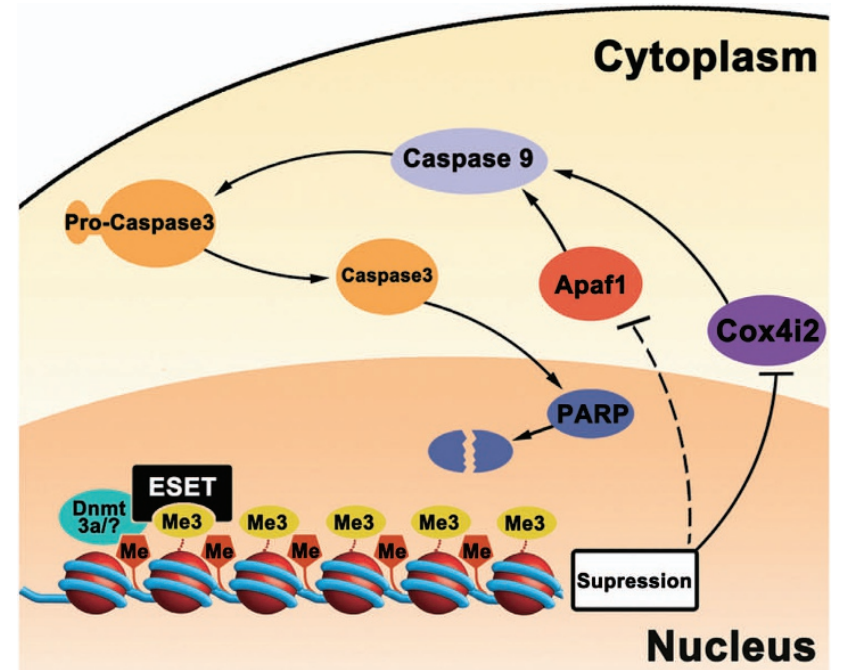

Figure 6 The schematic diagram of ESET regulation in SSCs. The schematic diagram demonstrates epigenetic regulation events in apoptosis process in spermatogonial stem/progenitor cells. ESET modulates H3K9me3, which represses the expression of Cox4i2 directly and also suppresses expression of Apaf1 via undetermined ways. Cox4i2 stimulates activation of Caspase9, which then cleaves downstream caspases (such as Caspase3) and PARP, leading to cell apoptosis

methylation in the promoter loci of Cox4i2, but not of Dazl, was influenced by ESET, indicating that ESET also regulate gene expression through DNA methylation in addition to histone methylation.

In conclusion, we showed that in SSCs, Cox4i2 expression was suppressed by ESET, which was recruited to the promoter of Cox4i2 and increased the level of H3K9me3 and DNA methylation which highly correlated with constitutive heterochromatin. SSC apoptosis caused by ESET depletion through derepressed Cox4i2 and further upregulated Caspase 9 which in turn activates effector Caspase 3 and cleavage of PARP (Figure 6).

\section{Materials and Methods}

Mice. Wild-type C57BL/6J and Kunming mice were used in our experiments. All animals were housed in a barrier facility under normal light and dark conditions with free access to food and water. All experimental procedures involving animals were approved by the Northwest A\&F University's Institutional Animal Care and Use Committee.

Cell culture. SSCs were cultured on plate with laminin-coated or Sertoli cell feeders. Primary Sertoli cells cultured using DMEM/F12 (Gibco, Grand Island, NY, USA) were supplemented with $10 \%$ FBS (Gibco). When Sertoli cells reached about $90 \%$ confluency, the cells were treated with mitomycin C (10 mg/l, Sigma, St. Louis, MO, USA) for $3 \mathrm{~h}$ and washed five times with PBS. SSCs culture medium consisted of DMEM/F12 (Gibco) supplemented with $1 \%$ FBS (Gibco), $30 \mathrm{ng} / \mathrm{ml} \beta$-estradiol (Gibco), $100 \mathrm{U} / \mathrm{ml}$ penicillin, $100 \mu \mathrm{g} / \mathrm{ml}$ streptomycin, $1 \times$ MEM non-essential amino acids, $20 \mathrm{ng} / \mathrm{ml}$ GDNF, $10 \mathrm{ng} / \mathrm{ml}$ mouse EGF, $10 \mathrm{ng} / \mathrm{ml}$ bFGF. The medium was changed every 2-3 days.

The C18-4 cell line was established from type A spermatogonia isolated from 6-day-old mouse testes. ${ }^{43}$ The cells were maintained in DMEM medium supplemented with $10 \%$ fetal calf serum, $1 \mathrm{mM}$ sodium pyruvate, $2 \mathrm{mM}$ glutamine, $50 \mathrm{U} / \mathrm{ml}$ penicillin, $50 \mu \mathrm{g} / \mathrm{ml}$ streptomycin and $100 \mathrm{mM}$ non-essential amino acids. The siRNA sequences targeting mouse ESET and Cox4i2 mRNA were designed and synthesized by Genepharma Company (Shanghai, China). The siRNAs were transfected into C18-4 cells using Lipofectamine2000 (Invitrogen, Carlsbad, CA, USA) according to the manufacturer's protocol.
Immunohistochemistry and antibodies. Testes from 3-month-old C57BL/6J mice were used for immunohistochemistry. The following primary antibodies were used: rabbit anti-ESET (1:50; Proteintech, Chicago, IL, USA), rabbit anti-H3K9me3 (1:500; Millipore, Billerica, MA, USA), goat anti-PLZF (1: 100; Santa Cruz, Dallas, TX, USA), goat anti-KIT (1:100, Santa Cruz) and goat anti-Thy 1 (1:150, Santa Cruz). The following secondary antibodies were used: Alexa 488-conjugated donkey anti-goat IgG and Alexa 594-conjugated donkey anti-rabbit IgG $(1: 400$, Invitrogen). Immunofluorescence images were obtained with a Nikon i90 microscope (Nikon, Tokyo, Japan).

RNAi lentivector construction and lentivirus production. The U6 RNAi cassette fragment from pSilencer 2.1-U6 hygro (Life Technologies, Carlsbad, CA, USA, AM5760) was amplified and cloned into PCDH-CMV-MCSEF1-GreenPuro (CD513B-1, SBI, Mountain View, CA, USA) to generate pCDH-U6MCS-EF1-GreenPuro Lentivector. A sequence specific to the mouse Eset CDNA used in the experiment was $5^{\prime}$-GGTGATGAGTACTTTGCAAAT-3'. A scramble sequence $\left(5^{\prime}\right.$-GATGAAATGGGTAAGTACA-3') was used as a negative control. HEK 293T cells were transfected with pCDH-U6-ESET/NC-shRNA and the other three plasmids ( $p G a g / P o l, p R e v, p V S V-G)$. Lentivirus-containing supernatants were collected and stored at $-80^{\circ} \mathrm{C}$. Lentivirus titers were identified by infecting $\mathrm{NIH} 3 \mathrm{~T} 3$ cells with viral supernatant for $16 \mathrm{~h}$. After incubation in fresh medium for an additional $48 \mathrm{~h}$, stably infected colonies were selected with puromycin $(2 \mu \mathrm{g} / \mathrm{ml})$ for 3 days, and viral titer was calculated by counting the TurboGFP-positive colonies (Life Technologies).

Testicular cell preparation and MACS. Testicular germ cell suspensions were obtained from Kunming mice at 6-8 days after birth using a two-step enzymatic digestion protocol. Sixty to eighty male mice were used in each experiment. Briefly, after removal of the tunica albuginea, the seminiferous tubules were digested with collagenase IV (1 mg/ml, Gibco) followed by digestion with $0.25 \%$ trypsin-EDTA (Hyclone, Erembodegem, Belgium) and DNase I $(1 \mathrm{mg} / \mathrm{ml}$, Gibco). Fetal bovine serum (Hyclone) was added to stop enzymatic digestion. The resulting cell suspension was filtered with a strainer (pore size: $40 \mu \mathrm{m}, \mathrm{BD}$ biosciences) and centrifuged at $600 \times g$ for $10 \mathrm{~min}$. Cells were preliminarily purified by differential plating.

Magnetic microbeads conjugated to anti-Thy1 antibody (30-H12; Miltenyi Biotec, Bergisch Gladbach, Germany) were used for MACS to enrich Thy1-positive cells. Briefly, the single-cell suspension $\left(1 \times 10^{7}\right.$ cells in $90 \mu$ l of MACS buffer) was incubated with $10 \mu$ of Thy 1 microbeads for 20 min at $4^{\circ} \mathrm{C}$. After rinsing with MACS buffer, Thy $1-$ negative cells were selected by passing through an MS separation column (Miltenyi Biotec) that was placed in a magnetic field. After removal of the column from the magnetic field, the magnetically retained Thy1-positive cells were eluted. The fraction of Thy1-positive cells was passed over a new prepared column for further purification.

Lentiviral transduction of mouse SSCs. Thy1-positive cells $\left(2 \times 10^{5}\right)$ were re-plated onto laminin-treated ( $20 \mu \mathrm{g} / \mathrm{ml}$, Sigma) 24 -well plates in DMEM/F12 (Gibco) with 5\% FBS (Gibco). The next day, SSCs (Thy1-positive cells) were transduced with Eset-shRNA lentivirus or NC-shRNA lentivirus $(\mathrm{MOI}=10)$, with polybrene $(4 \mu \mathrm{g} / \mathrm{ml}$, Sigma). After $12 \mathrm{~h}$ of culture, the medium was replaced with fresh SSCs culture medium. After 1 week of culture, cells were used for RNA and protein extraction, TUNEL analysis or microarray.

TUNEL staining. The cells were fixed in $4 \%$ paraformaldehyde for $40 \mathrm{~min}$ and incubate with $0.2 \%$ Triton X-100 for $30 \mathrm{~min}$ at room temperature. Cells were labeled using a One Step TUNEL Apoptosis Assay Kit (Beyotime, Jiangsu, China), according to the manufacturer's protocol. The nuclei were counterstained with Hoechst 33342 (Beyotime) to determine the percentage of TUNEL-positive nuclei relative to the total number of Hoechst-stained nuclei.

SSC transplantation. Mice were anesthetized by intraperitoneal injection of Avertin (Sigma). Donor lentivirus-infected SSCs $\left(1 \times 10^{6} \mathrm{cells} / \mathrm{ml}\right)$ were transplanted into the recipient mouse testis that was treated with busulfan to deplete endogenous germ cell 4 weeks before surgery (three replicates). About 10 weeks after transplantation, the recipient mouse testes were collected and used for protein extraction and immunohistochemistry. Testes of transplanted mice were fixed and embedded in paraffin. Sections were stained with hematoxylin and eosin and observed under a light microscope. The number of seminiferous tubule with (at least two layers of germ cells) or without spermatogenesis was counted and the proportion of the sections positive for spermatogenesis was recorded. The values 
for each transplantation group were determined in three replicates, in each of which at least five sections and an average of 80 tubules/section was examined.

Microarray analysis. SSCs (Thy1-positive cells), which were enriched through magnetic-activated cell sorting and transduced with Eset-shRNA or NC-shRNA lentiviral particles, were subjected to RNA extraction. Samples were RNA pool from three independent experiments. mRNA were reverse-transcribed, labeled and analyzed using the Roche NimbleScan microarray platform (Mouse $12 \times 135 \mathrm{~K}$ Gene Expression Array, NimbleGen Systems, Madison, WI, USA). Array was processed as per the manufacturer's instruction.

Quantitative RT-PCR (qRT-PCR). RNA was extracted from the cell or tissues with Trizol (Invitrogen) according to the manufacturer's protocol. RNA samples were subjected to reverse transcription using PrimeScript RT reagent Kit with gDNA Eraser (Takara, Dalian, China). Real-time PCR was performed with SYBR Green II PCR Mix (Takara) using an IQ5 (Bio-Rad, Berkeley, CA, USA). Reactions were run in triplicate in three independent experiments. The primer sequences are provided in Supplementary Table S1. Expression data were normalized to the geometric mean of housekeeping gene Gapdh to control the variability in expression levels and were analyzed using the $2^{-\Delta \Delta \mathrm{CT}}$ method.

Western blot. Protein concentration of the cell lysates was determined using a Bradford assay (Thermo Scientific, Rockford, IL, USA). Cell lysates were separated by SDS-PAGE, and transferred to PVDF membranes (Millipore). Membranes were probed using the following primary antibodies: anti-ESET (Proteintech, 1:1500), anti-Caspase9 (Proteintech; 1:1000), anti-H3K9me3 (Millipore, 1:2000), anti-Caspase3 (Santa Cruz and Proteintech, 1:1000), antiPLZF (Santa Cruz, 1:1000), anti-GFP (Beyotime, 1: 1000) and anti-PARP (Cell Signaling Technology, Danvers, MA, USA; 1:1000). Secondary antibodies were horseradish peroxidase-linked anti-rabbit or anti-goat antibody (Abcam, Cambridge, UK; $1: 5000$ ). Protein bands were visualized on a Bio-Rad Chemidoc XRS using a Western Bright ECL Kit (Advansta, Menlo Park, CA, USA).

ChIP. ChIP analysis was carried out using EZ-ChIP Kit (Upstate, Lake Placid, NY, USA) following the manufacturer's protocol. Formaldehyde-treated C18-4 cells were re-suspended in SDS lysis buffer, and the cell lysates were sheared by sonication. The chromatin fragments were immunoprecipitated with an antibody against ESET (Proteintech), H3K9me3 (Millipore), H4K20me3 (Millipore) and the purified DNA was analyzed by qPCR. The primer sequences are provided in Supplementary Table S2.

Bisulfite sequencing PCR. For bisulfite sequencing, cells were directly subjected to bisulfite conversion by using an EZ DNA Methylation Direct kit (Zymo Research, Orange, CA, USA). Bisulfite-modified DNAs were amplified (Supplementary Table S2). For sequence analysis, the PCR products obtained after bisulfite conversion were cloned into a pBackZero-T Vector (Takara), and six (Dazl) or nine (Cox4i2) individual clones were sequenced.

Statistical analysis. Data were expressed as the mean \pm S.E.M. Differences between groups were assessed using ANOVA with a Duncan's multiple range test (SPSS 12 for Windows; Chicago, IL, USA). A difference of $P<0.05$ was considered significant.

\section{Conflict of Interest}

The authors declare no conflict of interest.

Acknowledgements. We thank $\mathrm{Dr}$ Zuping He for his generous gift of mouse progenitor spermatogonia cell line C18-4 cells. We thank Dr Wai-Yee Chan and Mr Sean Zeng for English language editing of the manuscript. This work was supported by the National Basic Research Program of China (973 program; 2013CB943103), and the National Natural Science Foundation of China (Grant No. 31072029, No. 31272439 and №. 31230048).

1. Culty M. Gonocytes, the forgotten cells of the germ cell lineage. Birth Defects Res $C$ Embryo Today 2009; 87: 1-26.

2. Zheng $\mathrm{K}$, Wu $\mathrm{X}$, Kaestner $\mathrm{KH}$, Wang PJ. The pluripotency factor LIN28 marks undifferentiated spermatogonia in mouse. BMC Dev Biol 2009; 9: 38.
3. Eddy EM, Chen LY. Location, location, location: how does a spermatogonium know it is a spermatogonial stem cell (SSC)? Biol Reprod 2013; 88: 132.

4. Tegelenbosch RA, de Rooij DG. A quantitative study of spermatogonial multiplication and stem cell renewal in the C3H/101 F1 hybrid mouse. Mutat Res 1993; 290: 193-200.

5. Kubota H, Avarbock MR, Brinster RL. Growth factors essential for self-renewal and expansion of mouse spermatogonial stem cells. Proc Natl Acad Sci USA 2004; 101: 16489-16494.

6. Kokkinaki M, Lee TL, He Z, Jiang J, Golestaneh N, Hofmann MC et al. The molecular signature of spermatogonial stem/progenitor cells in the 6-day-old mouse testis. Biol Reprod 2009; 80: 707-717.

7. Shinohara T, Avarbock MR, Brinster RL. beta1- and alpha6-integrin are surface markers on mouse spermatogonial stem cells. Proc Natl Acad Sci USA 1999; 96: 5504-5509.

8. Alipoor FJ, Gilani MAS, Eftekhari-Yazdi P, Hampa AD, Hosseinifar $\mathrm{H}$, Alipour $\mathrm{H}$ et al. Achieving high survival rate following cryopreservation after isolation of prepubertal mouse spermatogonial cells. J Assist Reprod Genet 2009; 26: 143-149.

9. Brinster RL, Avarbock MR. Germline transmission of donor haplotype following spermatogonial transplantation. Proc Natl Acad Sci USA 1994; 91: 11303-11307.

10. Brinster RL, Zimmermann JW. Spermatogenesis following male germ-cell transplantation. Proc Natl Acad Sci USA 1994; 91: 11298-11302.

11. Khaira H, McLean D, Ohl DA, Smith GD. Spermatogonial stem cell isolation, storage, and transplantation. J Androl 2005; 26: 442-450.

12. Alipoor FJ, Gilani MA, Eftekhari-Yazdi P, Hampa AD, Hosseinifar $\mathrm{H}$, Alipour $\mathrm{H}$ et al. Achieving high survival rate following cryopreservation after isolation of prepubertal mouse spermatogonial cells. J Assist Reprod Genet 2009; 26: 143-149.

13. Meng X, Lindahl M, Hyvonen ME, Parvinen M, de Rooij DG. Hess MW et al. Regulation of cell fate decision of undifferentiated spermatogonia by GDNF. Science 2000; 287: 1489-1493.

14. He Z, Jiang J, Kokkinaki M, Golestaneh N, Hofmann MC, Dym M. Gdnf upregulates c-Fos transcription via the Ras/Erk1/2 pathway to promote mouse spermatogonial stem cell proliferation. Stem Cells 2008; 26: 266-278

15. Kubota $\mathrm{H}$, Avarbock MR, Brinster RL. Culture conditions and single growth factors affect fate determination of mouse spermatogonial stem cells. Biol Reprod 2004; 71: 722-731.

16. Ryu BY, Kubota H, Avarbock MR, Brinster RL. Conservation of spermatogonial stem cell self-renewal signaling between mouse and rat. Proc Natl Acad Sci USA 2005; 102: 14302-14307

17. Oatley JM, Avarbock MR, Telaranta Al, Fearon DT, Brinster RL. Identifying genes important for spermatogonial stem cell self-renewal and survival. Proc Natl Acad Sci USA 2006; 103: 9524-9529.

18. Buaas FW, Kirsh AL, Sharma M, McLean DJ, Morris JL, Griswold MD et al. Plzf is required in adult male germ cells for stem cell self-renewal. Nat Genet 2004; 36: 647-652.

19. Costoya JA, Hobbs RM, Barna M, Cattoretti G, Manova K, Sukhwani M et al. Essential role of Plzf in maintenance of spermatogonial stem cells. Nat Genet 2004; 36: 653-659.

20. Takashima S, Takehashi M, Lee J, Chuma S, Okano M, Hata K et al. Abnormal DNA methyltransferase expression in mouse germline stem cells results in spermatogenic defects. Biol Reprod 2009; 81: 155-164.

21. Iwamori N, Iwamori T, Matzuk MM. H3K27 demethylase, JMJD3, regulates fragmentation of spermatogonial cysts. PLoS One 2013; 8: e72689.

22. Fischle W, Wang Y, Allis CD. Histone and chromatin cross-talk. Curr Opin Cell Biol 2003: 15: $172-183$

23. Zhang $Y$, Reinberg $D$. Transcription regulation by histone methylation: interplay between different covalent modifications of the core histone tails. Genes Dev 2001; 15: 2343-2360.

24. Geiman TM, Robertson KD. Chromatin remodeling, histone modifications, and DNA methylation-how does it all fit together? J Cell Biochem 2002; 87: 117-125.

25. Harmston N, Lenhard B. Chromatin and epigenetic features of long-range gene regulation. Nucleic Acids Res 2013; 41: 7185-7199.

26. Nestorov $\mathrm{P}$, Tardat M, Peters $\mathrm{AH}$. H3K9/HP1 and Polycomb: two key epigenetic silencing pathways for gene regulation and embryo development. Curr Top Dev Biol 2013; 104: 243-291.

27. Dormann HL, Tseng BS, Allis CD, Funabiki H, Fischle W. Dynamic regulation of effector protein binding to histone modifications: the biology of HP1 switching. Cell Cycle 2006; 5 : 2842-2851.

28. Yang L, Xia L, Wu DY, Wang H, Chansky HA, Schubach WH et al. Molecular cloning of ESET, a novel histone $\mathrm{H} 3$-specific methyltransferase that interacts with ERG transcription factor. Oncogene 2002; 21: 148-152.

29. Yuan P, Han J, Guo G, Orlov YL, Huss M, Loh YH et al. Eset partners with Oct4 to restrict extraembryonic trophoblast lineage potential in embryonic stem cells. Genes Dev 2009; 23: 2507-2520.

30. Lohmann F, Loureiro J, Su H, Fang Q, Lei H, Lewis T et al. KMT1E mediated H3K9 methylation is required for the maintenance of embryonic stem cells by repressing trophectoderm differentiation. Stem Cells 2010; 28: 201-212.

31. Tan SL, Nishi M, Ohtsuka T, Matsui T, Takemoto K, Kamio-Miura A et al. Essential roles of the histone methyltransferase ESET in the epigenetic control of neural progenitor cells during development. Development 2012; 139: 3806-3816.

32. Lawson KA, Teteak CJ, Gao J, Li N, Hacquebord J, Ghatan A et al. ESET histone methyltransferase regulates osteoblastic differentiation of mesenchymal stem cells during postnatal bone development. FEBS Lett 2013; 587: 3961-3967.

33. Dodge JE, Kang YK, Beppu H, Lei H, Li E. Histone H3-K9 methyltransferase ESET is essential for early development. Mol Cell Biol 2004; 24: 2478-2486. 
34. Payne $C$, Braun RE. Histone lysine trimethylation exhibits a distinct perinuclear distribution in Plzf-expressing spermatogonia. Dev Biol 2006; 293: 461-472.

35. Verver D, van Pelt AM, Repping S, Hamer G. Role for rodent Smc6 in pericentromeric heterochromatin domains during spermatogonial differentiation and meiosis. Cell Death Dis 2013; 4: e749.

36. Gassei K, Orwig KE. SALL4 expression in gonocytes and spermatogonial clones of postnatal mouse testes. PLOS One 2013; 8: e53976.

37. Yang L, Wu W, Qi H. Gene expression profiling revealed specific spermatogonial stem cell genes in mouse. Genesis 2013; 51: 83-96.

38. Werler S, Demond H, Damm OS, Ehmcke J, Middendorff R, Gromoll J et al. Germ cell loss is associated with fading Lin28a expression in a mouse model for Klinefelter's syndrome. Reproduction 2014; 147: 253-264.

39. Guo Y, Hai Y, Gong Y, Li Z, He Z. Characterization, isolation, and culture of mouse and human spermatogonial stem cells. J Cell Physiol 2014; 229: 407-413.

40. Chakraborty P, Buaas FW, Sharma M, Snyder E, de Rooij DG, Braun RE. LIN28A marks the spermatogonial progenitor population and regulates its cyclic expansion. Stem Cells 2014; 32: 860-873.

41. Kanatsu-Shinohara M, Toyokuni S, Morimoto T, Matsui S, Honjo T, Shinohara T. Functional assessment of self-renewal activity of male germline stem cells following cytotoxic damage and serial transplantation. Biol Reprod 2003; 68: 1801-1807.

42. Zohni K, Zhang X, Tan SL, Chan P, Nagano MC. The efficiency of male fertility restoration is dependent on the recovery kinetics of spermatogonial stem cells after cytotoxic treatment with busulfan in mice. Hum Reprod 2012; 27: 44-53.

43. Hofmann MC, Braydich-Stolle L, Dettin L, Johnson E, Dym M. Immortalization of mouse germ line stem cells. Stem Cells 2005; 23: 200-210.

44. He Z, Jiang J, Kokkinaki M, Tang L, Zeng W, Gallicano I et al. MiRNA-20 and mirna-106a regulate spermatogonial stem cell renewal at the post-transcriptional level via targeting STAT3 and Ccnd1. Stem Cells 2013; 31: 2205-2217.

45. Zhang L, Tang J, Haines CJ, Feng H, Lai L, Teng $X$ et al. c-kit expression profile and regulatory factors during spermatogonial stem cell differentiation. BMC Dev Biol 2013; 13: 38 .

46. Sanchez-Alcazar JA, Ault JG, Khodjakov A, Schneider E. Increased mitochondrial cytochrome c levels and mitochondrial hyperpolarization precede camptothecin-induced apoptosis in Jurkat cells. Cell Death Differ 2000; 7: 1090-1100.
47. Borutaite V, Brown GC. Mitochondrial regulation of caspase activation by cytochrome oxidase and tetramethylphenylenediamine via cytosolic cytochrome c redox state. J Biol Chem 2007; 282: 31124-31130.

48. Zheng Y, He Y, An J, Qin J, Wang Y, Zhang Y et al. THY1 is a surface marker of porcine gonocytes. Reprod Fertil Dev 2014; 26: 533-539.

49. Gropp M, Itsykson P, Singer O, Ben-Hur T, Reinhartz E, Galun E et al. Stable genetic modification of human embryonic stem cells by lentiviral vectors. Mol Ther 2003; 7 : 281-287.

50. Ma Y, Ramezani A, Lewis R, Hawley RG, Thomson JA. High-level sustained transgene expression in human embryonic stem cells using lentiviral vectors. Stem Cells 2003; 21 : $111-117$.

51. Kim BJ, Kim KJ, Kim YH, Lee YA, Kim BG, Cho CM et al. Efficient enhancement of lentiviral transduction efficiency in murine spermatogonial stem cells. Mol Cells 2012; 33: 449-455.

52. Peters AH, Mermoud JE, O'Carroll D, Pagani M, Schweizer D, Brockdorff N et al. Histone $\mathrm{H} 3$ lysine 9 methylation is an epigenetic imprint of facultative heterochromatin. Nat Genet 2002; 30: 77-80.

53. Karimi MM, Goyal P, Maksakova IA, Bilenky M, Leung D, Tang JX et al. DNA methylation and SETDB1/H3K9me3 regulate predominantly distinct sets of genes, retroelements, and chimeric transcripts in mESCs. Cell Stem Cell 2011; 8: 676-687.

(c) (1) $(9) \Theta$ Cell Death and Disease is an open-access journal published by Nature Publishing Group. This work is licensed under a Creative Commons Attribution-NonCommercialNoDerivs 3.0 Unported License. The images or other third party material in this article are included in the article's Creative Commons license, unless indicated otherwise in the credit line; if the material is not included under the Creative Commons license, users will need to obtain permission from the license holder to reproduce the material. To view a copy of this license, visit http://creativecommons.org/licenses/ by-nc-nd/3.0/

Supplementary Information accompanies this paper on Cell Death and Disease website (http://www.nature.com/cddis) 